\title{
Oral symptoms and functional outcome related to oral and oropharyngeal cancer
}

\author{
Jolanda I. Kamstra • Harriet Jager-Wittenaar • Pieter U. Dijkstra • \\ Paulien M. Huisman • Rob P. van Oort • Bernard F. A. M. van der Laan • \\ Jan L. N. Roodenburg
}

Received: 17 September 2009 / Accepted: 12 July 2010 /Published online: 13 August 2010

(C) The Author(s) 2010. This article is published with open access at Springerlink.com

\begin{abstract}
Purpose This study aimed to assess: (1) oral symptoms of patients treated for oral or oropharyngeal cancer; (2) how patients rank the burden of oral symptoms; (3) the impact of the tumor, the treatment, and oral symptoms on functional outcome.

Methods Eighty-nine patients treated for oral or oropharyngeal cancer were asked about their oral symptoms related to mouth opening, dental status, oral sensory function, tongue mobility, salivary function, and pain. They were asked to rank these oral symptoms according to the degree of burden experienced. The Mandibular Function Impairment Questionnaire (MFIQ) was used to assess functional outcome. In a multivariate linear regression analyses, variables related to MFIQ scores $(p \leq 0.10)$ were entered as predictors with MFIQ score as the outcome. Results Lack of saliva (52\%), restricted mouth opening (48\%), and restricted tongue mobility (46\%) were the
\end{abstract}

J. I. Kamstra $(\varangle) \cdot$ H. Jager-Wittenaar $\cdot$ P. U. Dijkstra $\cdot$

R. P. van Oort · J. L. N. Roodenburg

Department of Oral and Maxillofacial Surgery and Special

Dentistry, University Medical Center Groningen,

University of Groningen,

PO Box 30.001, 9700 RB Groningen, The Netherlands

e-mail: j.i.kamstra@kchir.umcg.nl

P. U. Dijkstra

Department of Rehabilitation Medicine, Center for Rehabilitation, University Medical Center Groningen, University of Groningen, Groningen, The Netherlands

P. M. Huisman

Clinic for Periodontology,

Amsterdam, The Netherlands

B. F. A. M. van der Laan

Department of Otorhinolaryngology-Head \& Neck Surgery,

University Medical Center Groningen, University of Groningen,

Groningen, The Netherlands most frequently reported oral symptoms. Lack of saliva was most frequently (32\%) ranked as the most burdensome oral symptom.

For radiated patients, an inability to wear a dental prosthesis, a T3 or T4 stage, and a higher age were predictive of MFIQ scores. For non-radiated patients, a restricted mouth opening, an inability to wear a dental prosthesis, restricted tongue mobility, and surgery of the mandible were predictive of MFIQ scores.

Conclusions Lack of saliva was not only the most frequently reported oral symptom after treatment for oral or oropharyngeal cancer, but also the most burdensome. Functional outcome is strongly influenced by an inability to wear a dental prosthesis in both radiated and nonradiated patients.

Keywords Functional outcome.

Treatment related adverse events.

Oral and oropharyngeal cancer.

Oral symptoms · Radiotherapy ·

Mandibular function impairment questionnaire

\section{Introduction}

After oral and oropharyngeal cancer treatment, patients may report several oral symptoms, such as a restricted mouth opening, lack of saliva, an inability to wear a dental prosthesis or lack of retention of the prosthesis, loss of oral sensory function, and restricted tongue mobility [1-3]. These oral symptoms can have a negative influence on functional outcome.

Functional outcome after treatment for oral or oropharyngeal cancer is related to tumor site, tumor size, and the type of treatment received [4-8]. A study in patients treated for cancer of the base of the tongue, found 
that surgery which included the mandible (mandibulectomy or mandibulotomy) reduced functional outcome significantly more than surgery which did not include the mandible [5]. In that study, functional outcome was assessed by eating, speech, and diet (eating in public and normalcy of diet). Furthermore, reconstruction with freetissue transfer results in a significantly worse functional outcome when compared to direct reconstruction techniques $[5,6,8]$. Finally, a higher $\mathrm{T}$ stage (T3 or T4) and a larger resection size are also associated with a poorer functional outcome $[4-6,8]$.

In addition to tumor and treatment characteristics, oral symptoms may also impede functional outcome. A restricted mouth opening affects mandibular function, including chewing, eating, and swallowing, and may also impede oral hygiene, dental treatment, and oncological follow-up [9]. Lack of saliva, resulting from radiationinduced damage to the salivary glands or from removal of a salivary gland, impedes consolidation of a food bolus and functional outcome significantly $[10,11]$. Lack of retention and pain may inhibit biting and chewing in edentulous or partially dentate patients wearing a dental prosthesis [10]. Clinically, pain in the mouth can also impede functional outcome.

To study oral symptoms related to oral and oropharyngeal cancer, and their association with functional outcome, three aims were formulated for this study. The first was to assess oral symptoms of patients treated for oral or oropharyngeal cancer. Before treatment of oral or oropharyngeal cancer, most patients rank being cured as the most important outcome, followed by living as long as possible and having no pain. Only a few patients rank normal swallowing, normal taste, and normal salivation as important $[12,13]$. It is currently unclear which oral symptoms are most burdensome to patients after treatment of oral and oropharyngeal cancer. The second aim was therefore to assess how patients rank the burden of their oral symptoms. Finally, oral or oropharyngeal cancer and the consequences of treatment can influence mandibular functioning (Fig. 1). However, it is unclear which factors have the largest impact on functional outcome. The third aim was to analyze the impact of the tumor, cancer treatment, and oral symptoms on functional outcome.

\section{Patients and methods}

\section{Patients}

Patients aged $\geq 18$ years, who were treated for oral or oropharyngeal cancer at the department of Oral and Maxillofacial Surgery, Division Oncology, University Medical Center Groningen, the Netherlands, were invited to

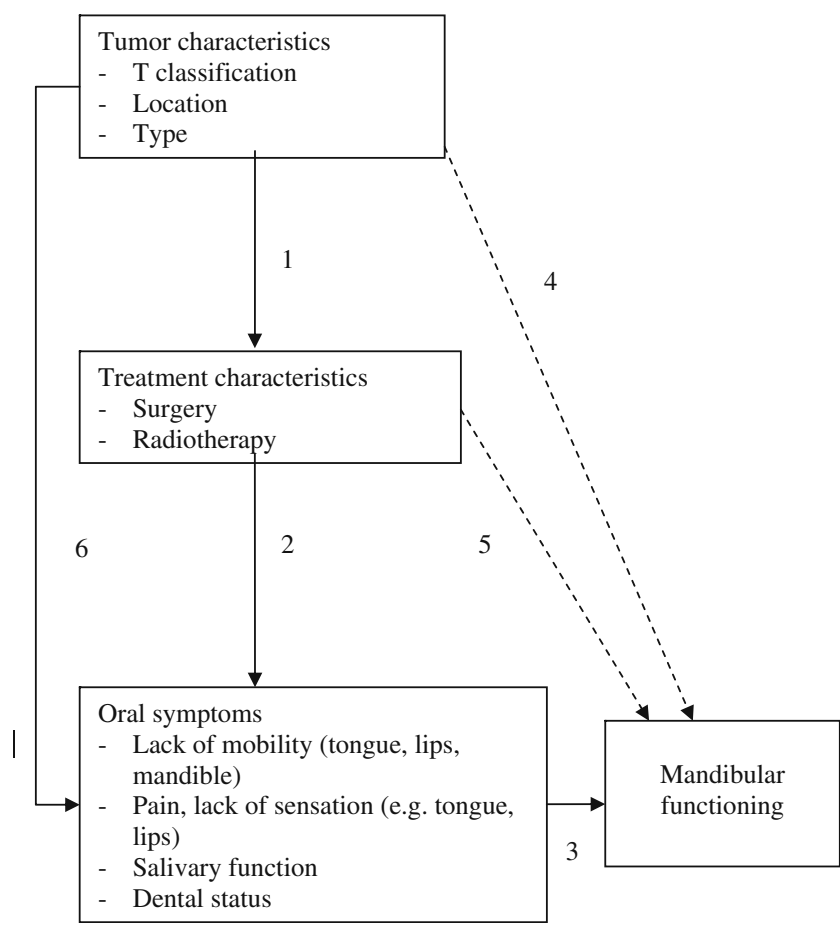

Fig. 1 Clinical model of factors influencing mandibular functioning. Within this study, a clinical model of factors influencing mandibular functioning was hypothesized and analyzed: (1) Tumor characteristics determine treatment modalities (extent of surgery, dose of radiotherapy, etc.). (2) Besides anti-tumor effects, treatments also induce adverse effects, resulting in oral symptoms. (3) These oral symptoms may result in restrictions in mandibular functioning. $(4,5)$ However, it is possible that some tumor characteristics or treatment characteristics influence mandibular functioning directly without actually resulting in specific oral symptoms. (6) Finally, tumor characteristics may induce oral symptoms directly

participate in this cross-sectional study. Patients were informed about the study by means of a letter sent 1 week prior to their regular follow-up appointment. During this appointment, the physician further informed the patient and invited them to participate. Assessment was performed after patients signed a written informed consent.

Included in the study were patients who had completed their treatment for oral or oropharyngeal cancer at least 6 months before study assessment. Treatment consisted of surgery or a combination of surgery and radiotherapy. Excluded were patients who did not have sufficient understanding of Dutch to be interviewed or patients who were physically or mentally not fit enough to participate. Information regarding the type and localization of the tumor, TN classification, and type of treatment (surgery, radiotherapy) was retrieved from the medical records.

Oral symptoms

Assessment of oral symptoms was performed by one observer $(\mathrm{PMH})$, who asked whether the patient: 
- experienced a restricted mouth opening (yes/no)

- was able to wear a dental prosthesis (in case of an edentulous mandible or maxilla, or a partially dentate mandible or maxilla; yes/no)

- experienced lack of retention of the dental prosthesis (yes/no)

- experienced a loss of sensory function of the tongue (yes/no), lips (yes/no), or elsewhere in the mouth (yes/ no)

- $\quad$ experienced a restricted tongue mobility (yes/no), or lip mobility (yes/no)

- $\quad$ experienced lack of saliva (yes/no)

- experienced an excess of saliva (yes/no)

- experienced pain in the mouth (yes/no)

- experienced other symptoms, and if so, what kind of symptoms.

These questions were the result of a consensus between two experts (RPO, oral maxillofacial prosthetist, and JLNR, oral maxillofacial surgeon oncologist). These experts were asked to list the most frequently reported oral symptoms of patients being treated for oral and oropharyngeal cancer. Additionally, the patient was asked to rank the burden of their oral symptoms. The three most burdensome oral symptoms were recorded.

\section{Functional outcome}

Functional outcome was assessed by the Mandibular Function Impairment Questionnaire (MFIQ). This questionnaire consists of 11 items assessing perceived difficulties in mandibular function during social activities, speaking, taking a large bite, chewing hard food, chewing soft food, work and/or daily activities, drinking, laughing, chewing resistant food, yawning, and kissing. Additionally, six items assess perceived difficulties in mandibular function when eating a hard cookie, eating meat, eating a raw carrot, eating French bread, eating peanuts/almonds, and eating an apple. Eating includes taking a bite, chewing, and swallowing. Possible answers were: 0 , no difficulty; 1 , a little difficulty; 2, quite a bit of difficulty; 3, much difficulty; and 4, very much difficulty or impossible without help. The scores are added to give a sum score (range 0-68). A higher score indicates more perceived mandibular function impairments and a MFIQ score of ' 0 ' indicates no impairment in mandibular functioning. Internal consistency of the questionnaire ranges between 0.80 and 0.95 [14]. The outcome of the questionnaire is independent of the method applied, whether by interview or filled out by the patient $(r=0.95)$ [14]. The MFIQ has previously been used to assess mandibular function after treatment of a chronic closed lock, subacute non-specific temporomandibular disorders, a painful disc displacement, and to determine a functional cutoff point for trismus [15-18].

\section{Statistical analysis}

Statistical analysis was performed using SPSS 16.0 for Windows software (SPPS Inc., Chicago, IL, USA). Statistical analysis included univariate analyses and multivariate linear regression analyses.

In the univariate analyses, associations between MFIQ scores and possible predictors were analyzed by means of independent samples $t$ test and Pearson's correlation coefficient $(r)$.

Possible predictors included age (years), gender (male/ female), dental status (dentate/edentulous), T stage (T1/T2 versus T3/T4), radiotherapy (yes, no), surgery of the mandible (yes, no), interval between last oncology treatment and time of assessment (years), and oral symptoms: lack of saliva, restricted mouth opening, reduced tongue mobility, lack of retention of the prosthesis, reduced sensation of the lips, inability to wear a prosthesis, reduced sensation of the tongue, restricted mobility of the lips, reduced sensation elsewhere in mouth, pain in the mouth, excessive saliva, and swallowing problems (yes, no).

In the multivariate linear regression analysis, MFIQ score was used as the outcome variable. Variables related to MFIQ score in the univariate analyses $(p \leq 0.10)$ were entered as predictors (stepwise backward, entry criterion $p \leq 0.05$, removal criterion $p>0.10$ ). Interaction effects between the predictor variables were explored.

\section{Results}

One hundred and one patients were asked to participate. Twelve patients did not fulfill the inclusion criteria or refused to participate in the study, giving 89 patients $(88 \%)$ to participate in the study. Patient characteristics, tumor type, tumor localization, and treatment received are summarized in Table 1. Median interval (inter quartile range) between the last oncology treatment and the time of assessment was 1.7 years ( 0.9 to 4.1 years). The mean MFIQ score was 24.3 (SD 16.9). MFIQ score of radiated patients (mean 28.9, SD 14.9) was significantly higher than that of non-radiated patients (mean 16.7, SD 17.6, $p=$ $0.001)$. Most patients (76\%) were treated for a squamous cell carcinoma, which was most frequently located in the tongue $(36 \%)$. Sixty-three percent of the patients were treated with radiotherapy.

Twenty patients $(22 \%)$ did not wear their dental prosthesis during the assessment, of which eight patients did not wear their upper dentures and 12 patients did not 
Table 1 Characteristics of patients, tumor type, tumor localization, and tumor treatment

\begin{tabular}{|c|c|c|c|}
\hline Variables & & & \\
\hline $\begin{array}{l}\text { Age (years) interval between } \\
\text { last oncology treatment and }\end{array}$ & $\begin{array}{l}\text { Median (inter } \\
\text { quartile range) }\end{array}$ & $\begin{array}{l}\mathrm{Me} \\
61 . \mathrm{C}\end{array}$ & $\begin{array}{l}(\mathrm{SD}) \\
14.0)\end{array}$ \\
\hline MFIQ score (scoring & & 24.3 & 16.9) \\
\hline & & $\%$ & $n$ \\
\hline Gender & & & \\
\hline Male & & 57 & 51 \\
\hline Female & & 43 & 38 \\
\hline Tumor type & & & \\
\hline Squamous cell carcinoma & & 76 & 68 \\
\hline Salivary gland tumor & & 18 & 16 \\
\hline Other & & 6 & 5 \\
\hline Tumor localization ${ }^{\mathrm{a}}$ & & & \\
\hline Tongue & & 36 & 32 \\
\hline Alveolar process of the mandible & & 24 & 21 \\
\hline Floor of mouth & & 19 & 17 \\
\hline Alveolar process of the maxilla & & 11 & 10 \\
\hline Salivary gland & & 11 & 10 \\
\hline Soft palate & & 11 & 10 \\
\hline Lip & & 10 & 9 \\
\hline Pharyngeal arch & & 8 & 7 \\
\hline Cheek & & 7 & 6 \\
\hline Base of the tongue & & 7 & 6 \\
\hline Tonsil & & 5 & 4 \\
\hline $\begin{array}{l}\text { Lateral and dorsal wall of the } \\
\text { oropharynx }\end{array}$ & & 2 & 2 \\
\hline Buccogingival vault of the maxilla & & 1 & 1 \\
\hline Buccogingival vault of the mandible & & 1 & 1 \\
\hline Other $^{\mathrm{b}}$ & & 1 & 1 \\
\hline Radiotherapy & & & \\
\hline Yes & & 63 & 56 \\
\hline No & & 37 & 33 \\
\hline Surgery of the mandible & & & \\
\hline Yes & & 28 & 25 \\
\hline No & & 72 & 64 \\
\hline
\end{tabular}

${ }^{\mathrm{a}} N=137$. In $67 \%$ of the patients, the tumor was located on one site. In the other patients, the tumor extended over several regions. Therefore, the total number of localizations exceeded the total number of patients

${ }^{\mathrm{b}}$ Nasopharynx

wear their lower dentures. Five patients wore neither their upper or lower dentures (Table 2).

The TN classification could be found in the medical records for $75 \%$ of the patients (Table 3 ). Patients with a missing TN classification were treated further in the past (mean 4.4, SD 4.2 years) than patients with a recorded TN classification (mean 2.8, SD 3.9 years, $p=0.138$ ). Patients
Table 2 Dental status

\begin{tabular}{|c|c|c|c|c|}
\hline Dental status & $\begin{array}{l}\text { Mandible } \\
\text { dentate }\end{array}$ & $\begin{array}{l}\text { Mandible } \\
\text { partially dentate }\end{array}$ & $\begin{array}{l}\text { Mandible } \\
\text { edentulous }\end{array}$ & Tota \\
\hline Maxilla dentate & 13 & 5 & - & 18 \\
\hline $\begin{array}{l}\text { Maxilla } \\
\text { partially dentate }\end{array}$ & 5 & 9 & 3 & 17 \\
\hline $\begin{array}{l}\text { Maxilla } \\
\text { edentulous }\end{array}$ & - & 8 & 46 & 54 \\
\hline Total & 18 & 22 & 49 & 89 \\
\hline
\end{tabular}

with a missing TN classification were also more likely to have been previously treated in another medical center.

Lack of saliva was the most frequently reported oral symptom (52\%), followed by a restricted mouth opening $(48 \%)$ and restricted tongue mobility (46\%). Lack of saliva was ranked as the most burdensome oral symptom by $32 \%$ of patients. Restricted tongue mobility and restricted mouth opening were ranked equally burdensome by $14 \%$ of patients (Table 4 ).

A significant interaction between radiotherapy and restricted mouth opening was found to predict MFIQ scores. Therefore, the relationship between predictive variables and MFIQ scores were analyzed separately for radiated and non-radiated patients. In radiated patients, age, gender, restricted mouth opening, an inability to wear a dental prosthesis, surgery of the mandible, being fully edentulous, and $\mathrm{T}$ stage were significantly related to MFIQ scores $(p \leq 0.10)$. In non-radiated patients, a restricted mouth opening, restricted tongue mobility, reduced sensation elsewhere in mouth (other than tongue or lip), restricted lip mobility, reduced tongue sensation, an inability to wear a dental prosthesis, surgery of the mandible, and being fully edentulous were significantly related to MFIQ scores $(p \leq 0.10)$. For radiated patients, an inability to wear a dental prosthesis, $\mathrm{T}$ stage (T3/T4), and

Table 3 TN classification on the basis of the pathology report

\begin{tabular}{llllll}
\hline Status & T1 & T2 & T3 & T4 & Total \\
\hline N0 & 20 & 13 & 5 & 8 & 46 \\
N1 & 2 & 1 & 2 & 1 & 6 \\
N2 & 1 & - & - & - & 1 \\
N2b & 1 & 4 & 1 & 6 & 12 \\
N2c & - & - & - & 1 & 1 \\
N3 & - & 1 & - & - & 1 \\
Total & 24 & 19 & 8 & 16 & 67 \\
\hline
\end{tabular}

TN classification was present in the medical records of 67 patients $(75 \%)$ 
Table 4 Oral symptoms reported by 89 patients treated for oral or oropharyngeal cancer and ranking of symptoms according to their perceived burden

\begin{tabular}{|c|c|c|c|c|c|}
\hline $\begin{array}{l}\text { Oral } \\
\text { symptoms }\end{array}$ & Percent & $n$ & $\begin{array}{l}\text { Most } \\
\text { burdening } \\
\text { symptom }(n \\
=88) ; \%\end{array}$ & $\begin{array}{l}\text { Second } \\
\text { most } \\
\text { burdening } \\
\text { symptom } \\
(n=72) ; \%\end{array}$ & $\begin{array}{l}\text { Third most } \\
\text { burdening } \\
\text { symptom } \\
(n=56) ; \%\end{array}$ \\
\hline Lack of saliva & 52 & 46 & 32 & 11 & 5 \\
\hline $\begin{array}{l}\text { Restricted } \\
\text { mouth } \\
\text { opening }\end{array}$ & 48 & 42 & 14 & 14 & 18 \\
\hline $\begin{array}{l}\text { Reduced } \\
\text { tongue } \\
\text { mobility }\end{array}$ & 46 & 41 & 14 & 24 & 13 \\
\hline $\begin{array}{l}\text { Lack of } \\
\text { retention of } \\
\text { the prosthesis }\end{array}$ & 39 & 34 & 9 & 10 & 5 \\
\hline $\begin{array}{l}\text { Reduced } \\
\text { sensation of } \\
\text { the lips }\end{array}$ & 30 & 27 & 6 & 11 & 7 \\
\hline $\begin{array}{l}\text { Inability to } \\
\text { wear a } \\
\text { prosthesis }\end{array}$ & 28 & 25 & 9 & 7 & 9 \\
\hline $\begin{array}{l}\text { Reduced } \\
\text { sensation of } \\
\text { the tongue }\end{array}$ & 27 & 24 & 7 & 8 & 13 \\
\hline $\begin{array}{l}\text { Restricted } \\
\text { mobility of } \\
\text { the lips }\end{array}$ & 25 & 22 & 3 & 6 & 9 \\
\hline $\begin{array}{l}\text { Reduced } \\
\text { sensation } \\
\text { elsewhere in } \\
\text { the mouth }\end{array}$ & 23 & 20 & 5 & 4 & 9 \\
\hline $\begin{array}{l}\text { Pain in the } \\
\text { mouth }\end{array}$ & 17 & 15 & 2 & 4 & 5 \\
\hline $\begin{array}{l}\text { Excess of } \\
\text { saliva }\end{array}$ & 6 & 5 & - & - & - \\
\hline $\begin{array}{l}\text { Swallowing } \\
\text { problems }\end{array}$ & 6 & 5 & - & - & - \\
\hline
\end{tabular}

Some patients reported only the most burdensome oral symptom $(n=$ 88 ) whereas others also reported the second or third most burdensome oral symptoms

older age were predictive of higher MFIQ scores. For nonradiated patients, restricted mouth opening, an inability to wear a dental prosthesis, restricted tongue mobility, and surgery of the mandible were predictive of higher MFIQ scores (Table 5).

\section{Discussion}

The current study demonstrated that lack of saliva was not only the most frequently reported oral symptom after treatment for oral or oropharyngeal cancer, but also the most burdensome, with almost one third of the patients ranking it highest. This finding has been reported previously [19]. Radiotherapy causes damage to the salivary glands, resulting in reduced volume and altered composition of saliva [3]. The consistency of saliva changes from thin to thick, with a reduced $\mathrm{pH}$ and buffering capacity $[3,19]$. In addition to dryness of the mouth and thirst, lack of saliva may cause an accumulation of mucus, a burning sensation, taste disturbances, difficulties in oral functioning, and problems wearing dentures [3].

A restricted mouth opening and restricted tongue mobility were reported by almost half of the patients. These oral symptoms were reported among the three most burdensome. Both symptoms are known to occur frequently after treatment for oral or oropharyngeal cancer [20, 21]. Despite the fact that lack of saliva was most frequently mentioned and was ranked most burdensome for many patients, it was not predictive for functional outcome. Generally, lack of saliva is perceived as very inconvenient, however, patients may compensate by using artificial saliva or by drinking during meals [4, 22]. Most patients prefer water as a lubricant [3]. It might also be possible that the influence of lack of saliva on the regression analyses was obscured by low statistical power.

A mean MFIQ score of 24.3 was found, indicating that averagely patients experience a substantial amount of mandibular impairment after treatment of oral and oropharyngeal cancer. The finding that radiated patients had a poorer functional outcome than non-radiated patients has been described previously [23]. However, for radiated patients and non-radiated patients the MFIQ scores were predicted by different variables. The only common variable in the regression analyses an inability to wear dental prosthesis. In non-radiated patients the impact on functional outcome was slightly larger $(\beta=14.3)$ than in radiated patients $(\beta=10.5)$. Edentulous or partially dentate patients may not be able to wear a dental prosthesis because of lack of retention resulting from anatomical changes post surgery. Pain may also prevent patients from wearing dentures, resulting in problems with biting and chewing food [1]. Patients who are fitted with a dental prosthesis are known to have a better functional outcome than those who are not fitted with prosthesis, based on List's Performance Status Scale [10].

In the current study, a higher $\mathrm{T}$ stage was associated with poorer functional outcome. As this relationship was found only in radiated patients, the $\mathrm{T}$ stage may have acted as a confounding variable. Patients with larger tumors (T3, T4) generally undergo combined treatment, this treatment results in greater tissue damage and scar formation further impeding mandibular function.

In radiated patients, an older age predicted poorer mandibular function. This relationship might be explained by normal aging processes and additional comorbidity, known to be more frequent as age increases. Comorbidity is negatively associated with 
Table 5 Results of multivariate linear regression analyses to predict the score on the MFIQ

\begin{tabular}{|c|c|c|c|c|}
\hline MFIQ score (scale range $0-68$ ) & $\beta$ & SE & $95 \%$ CI $\beta$ & Significance of $\beta$ \\
\hline \multicolumn{5}{|l|}{ Radiated patients } \\
\hline Not being able to wear a dental prosthesis ${ }^{a}$ & 10.5 & 4.2 & 2.1 to 18.9 & $p=0.016$ \\
\hline T stage & 6.9 & 4.2 & -1.5 to 15.3 & $p=0.103$ \\
\hline $\mathrm{Age}^{\mathrm{b}}$ & 0.5 & 0.1 & 0.2 to 0.8 & $p<0.001$ \\
\hline Constant & -7.8 & 8.5 & -24.9 to 9.4 & $p=0.366$ \\
\hline \multicolumn{5}{|l|}{$r^{2}=0.45$} \\
\hline \multicolumn{5}{|l|}{ Non-radiated patients } \\
\hline Restricted mouth opening ${ }^{\mathrm{a}}$ & 22.9 & 3.9 & 14.9 to 30.9 & $p<0.001$ \\
\hline Not being able to wear a dental prosthesis ${ }^{\mathrm{a}}$ & 14.3 & 4.9 & 4.4. to 24.3 & $p=0.006$ \\
\hline Restricted tongue mobility ${ }^{a}$ & 13.0 & 3.8 & 5.2 to 20.9 & $p=0.002$ \\
\hline Surgery of the mandible ${ }^{\mathrm{a}}$ & 12.8 & 6.3 & -0.1 to 25.7 & $p=0.052$ \\
\hline Constant & 1.5 & 2.5 & -3.7 to 6.7 & $p=0.564$ \\
\hline$r^{2}=0.72$ & & & & \\
\hline
\end{tabular}

$\beta$ Regression coefficient, $S E$ standard error of $\beta, 95 \%$ CI $\beta 95 \%$ confidence interval of the regression coefficient, $r^{2}$ explained variance of the regression model

${ }^{\mathrm{a}}$ Yes $=1$, no $=0$

${ }^{\mathrm{b}}$ Per year

swallowing function after surgical treatment for advanced oral or oropharyngeal cancer [23]. A restricted mouth opening was expected to be a strong predictor of poor mandibular function in radiated patients. However, a restricted mouth opening appeared to have the largest effect in non-radiated patients [24]. Nevertheless, restricted mouth opening, as well as restricted tongue mobility, is well known for negatively affecting oral functioning [21, 25].

It is clear that an inability to wear a dental prosthesis greatly impedes mandibular functioning. Therefore, providing patients, both radiated and non-radiated, with a dental prosthesis is an important measure to reduce mandibular impairment. Clinically, the dental prosthesis should have an optimal retention, although retention was not a significant factor in the regression analysis. Additionally, for non-radiated patients, treatment of restricted mouth opening and restricted tongue mobility may reduce mandibular impairment.

Rehabilitation of patients after treatment for oral or oropharyngeal cancer should focus on preserving mouth opening and tongue mobility. However, preservation of mouth opening after radiation therapy is difficult. The average reduction in mouth opening ranges from $18 \%$ to $32 \%$, with the greatest decrease occurring between 1 and 9 months after radiotherapy [26, 27]. The currently frequently applied intensity-modulated radiotherapy reduces mouth opening less than conventional radiotherapy [28]. Once mouth opening has decreased, it is difficult to achieve improvement. The effects of exercises on a restricted mouth opening after oral or oropharyngeal cancer are limited with in a mean increase of 5 to $6 \mathrm{~mm}$ [29]. TheraBite ${ }^{\circledR}$ treatment seems to be effective [30]. Restricted tongue mobility may be improved by speech therapy, including range of motion exercises [31-33].

Strengths of this study include the use of a standardized, valid, and reliable questionnaire, and the assessment of multiple symptoms related to oral and oropharyngeal cancer. Limitations of the current study include the relatively small sample size which hampered statistical analysis, the cross-sectional study design, and the substantial number of missing data regarding $\mathrm{T}$ stage in the medical records.

More insight into the development of oral symptoms is needed to determine which should be prevented in order to maintain mandibular function and achieve optimal functional outcome.

\section{Conclusions}

Lack of saliva is not only the most frequently reported oral symptom after treatment for oral or oropharyngeal cancer, but also the most burdensome. Functional outcome is strongly influenced by an inability to wear a dental prosthesis in both radiated and non-radiated patients. 
Open Access This article is distributed under the terms of the Creative Commons Attribution Noncommercial License which permits any noncommercial use, distribution, and reproduction in any medium, provided the original author(s) and source are credited.

\section{References}

1. Chambers MS, Garden AS, Kies MS, Martin JW (2004) Radiation-induced xerostomia in patients with head and neck cancer: pathogenesis, impact on quality of life, and management. Head Neck 26:796-807

2. Finlay PM, Dawson F, Robertson AG, Soutar DS (1992) An evaluation of functional outcome after surgery and radiotherapy for intraoral cancer. Br J Oral Maxillofac Surg 30:14-17

3. Vissink A, Jansma J, Burlage FR, Coppes RP (2003) Oral sequelae of head and neck radiotherapy. Crit Rev Oral Biol Med 14:199-212

4. Konstantinovic VS (1999) Quality of life after surgical excision followed by radiotherapy for cancer of the tongue and floor of the mouth: evaluation of 78 patients. J Craniomaxillofac Surg 27:192-197

5. Malone JP, Stephens JA, Grecula JC, Rhoades CA, Ghaheri BA, Schuller DE (2004) Disease control, survival, and functional outcome after multimodal treatment for advanced-stage tongue base cancer. Head Neck 26:561-572

6. Rogers SN, Lowe D, Brown JS, Vaughan ED (1999) The University of Washington head and neck cancer measure as a predictor of outcome following primary surgery for oral cancer. Head Neck 21:394-401

7. Rogers SN, Lowe D, Fisher SE, Brown JS, Vaughan ED (2002) Health-related quality of life and clinical function after primary surgery for oral cancer. Br J Oral Maxillofac Surg 40:11-18

8. Zuydam AC, Lowe D, Brown JS, Vaughan ED, Rogers SN (2005) Predictors of speech and swallowing function following primary surgery for oral and oropharyngeal cancer. Clin Otolaryngol 30:428-437

9. Scott B, Butterworth C, Lowe D, Rogers SN (2008) Factors associated with restricted mouth opening and its relationship to health-related quality of life in patients attending a Maxillofacial Oncology clinic. Oral Oncol 44(5):430-8

10. Teoh KH, Patel S, Hwang F, Huryn JM, Verbel D, Zlotolow IM (2005) Prosthetic intervention in the era of microvascular reconstruction of the mandible-a retrospective analysis of functional outcome. Int J Prosthodont 18:42-54

11. Logemann JA, Smith CH, Pauloski BR, Rademaker AW, Lazarus CL, Colangelo LA, Mittal B, MacCracken E, Gaziano J, Stachowiak L, Newman LA (2001) Effects of xerostomia on perception and performance of swallow function. Head Neck 23:317-321

12. List MA, Stracks J, Colangelo L, Butler P, Ganzenko N, Lundy D, Sullivan P, Haraf D, Kies M, Goodwin W, Vokes EE (2000) How do head and neck cancer patients prioritize treatment outcomes before initiating treatment? J Clin Oncol 18:877-884

13. List MA, Rutherford JL, Stracks J, Pauloski BR, Logemann JA, Lundy D, Sullivan P, Goodwin W, Kies M, Vokes EE (2004) Prioritizing treatment outcomes: head and neck cancer patients versus nonpatients. Head Neck 26:163-170

14. Stegenga B, de Bont LGM, de Leeuw R, Boering G (1993) Assessment of mandibular function impairment associated with temporomandibular joint osteoarthrosis and internal derangement. J Orofac Pain 7:183-195

15. Dijkstra PU, Huisman PM, Roodenburg JLN (2006) Criteria for trismus in head and neck oncology. Int J Oral Maxillofac Surg $35: 337-342$
16. Fricton JR, Look JO, Schiffman E, Swift J (2002) Long-term study of temporomandibular joint surgery with alloplastic implants compared with nonimplant surgery and nonsurgical rehabilitation for painful temporomandibular joint disc displacement. J Oral Maxillofac Surg 60:1400-1411

17. Pereira LJ, Steenks MH, de Wijer A, Speksnijder CM, van der Bilt A (2009) Masticatory function in subacute TMD patients before and after treatment. J Oral Rehabil 36:391-402

18. Politi M, Sembronio S, Robiony M, Costa F, Toro C, Undt G (2007) High condylectomy and disc repositioning compared to arthroscopic lysis, lavage, and capsular stretch for the treatment of chronic closed lock of the temporomandibular joint. Oral Surg Oral Med Oral Pathol Oral Radiol Endod 103:27-33

19. Dirix P, Nuyts S, Vander Poorten V, Delaere P, Van den Bogaert W (2007) Efficacy of the BioXtra dry mouth care system in the treatment of radiotherapy-induced xerostomia. Support Care Cancer 15:1429-1436

20. Bensadoun RJ, Riesenbeck D, Lockhart PB, Elting LS, Spijkervet FK, Brennan MT (2010) A systematic review of trismus induced by cancer therapies in head and neck cancer patients. Support Care Cancer

21. Pauloski BR (2008) Rehabilitation of dysphagia following head and neck cancer. Phys Med Rehabil Clin N Am 19:889-928, x

22. Atkinson JC, Fox PC (1992) Salivary gland dysfunction. Clin Geriatr Med 8:499-511

23. Kreeft AM, van der Molen L, Hilgers FJ, Balm AJ (2009) Speech and swallowing after surgical treatment of advanced oral and oropharyngeal carcinoma: a systematic review of the literature. Eur Arch Otorhinolaryngol 266:1687-1698

24. Scott B, D'Souza J, Perinparajah N, Lowe D, Rogers SN (2010) Longitudinal evaluation of restricted mouth opening (trismus) in patients following primary surgery for oral and oropharyngeal squamous cell carcinoma. Br J Oral Maxillofac Surg (in press)

25. Van Cann EM, Dom M, Koole R, Merkx MA, Stoelinga PJ (2005) Health related quality of life after mandibular resection for oral and oropharyngeal squamous cell carcinoma. Oral Oncol 41:687693

26. Goldstein M, Maxymiw WG, Cummings BJ, Wood RE (1999) The effects of antitumor irradiation on mandibular opening and mobility: a prospective study of 58 patients. Oral Surg Oral Med Oral Pathol Oral Radiol Endod 88:365-373

27. Wang CJ, Huang EY, Hsu HC, Chen HC, Fang FM, Hsiung CY (2005) The degree and time-course assessment of radiationinduced trismus occurring after radiotherapy for nasopharyngeal cancer. Laryngoscope 115:1458-1460

28. Hsiung CY, Huang EY, Ting HM, Huang HY (2008) Intensitymodulated radiotherapy for nasopharyngeal carcinoma: the reduction of radiation-induced trismus. $\mathrm{Br} \mathrm{J}$ Radiol 81:809814

29. Dijkstra PU, Sterken MW, Pater R, Spijkervet FKL, Roodenburg JLN (2006) Exercise therapy for trismus in head and neck cancer. Oral Oncol 43:389-394

30. Buchbinder D, Currivan RB, Kaplan AJ, Urken ML (1993) Mobilization regimens for the prevention of jaw hypomobility in the radiated patient: a comparison of three techniques. J Oral Maxillofac Surg 51:863-867

31. Logemann JA, Rademaker AW, Pauloski BR, Kahrilas PJ (1994) Effects of postural change on aspiration in head and neck surgical patients. Otolaryngol Head Neck Surg 110:222-227

32. Logemann JA, Pauloski BR, Rademaker AW, Colangelo L (1997) Speech and swallowing rehabilitation for head and neck cancer patients. Oncology (Williston Park) 11:651-656

33. Rasley A, Logemann JA, Kahrilas PJ, Rademaker AW, Pauloski BR, Dodds WJ (1993) Prevention of barium aspiration during videofluoroscopic swalling studies: value of change in posture. Am J Radiol 160:1005-1009 